\title{
Simulating plant invasion dynamics in mountain ecosystems under global change scenarios
}

\author{
Marta Carboni ${ }^{1}$ (C) | Maya Guéguen ${ }^{1}$ | Ceres Barros ${ }^{1}$ (C) | Damien Georges ${ }^{1,2}$ | \\ Isabelle Boulangeat ${ }^{3}$ | Rolland Douzet $^{4}$ | Stefan Dullinger ${ }^{5}$ | Guenther Klonner ${ }^{5}$ | \\ Mark van Kleunen $^{6}$ | Franz Essl ${ }^{5}$ | Oliver Bossdorf ${ }^{7}$ | Emily Haeuser ${ }^{6}$ | Matthew
} V. Talluto ${ }^{1}$ | Dietmar Moser ${ }^{5}$ | Svenja Block ${ }^{7}$ | Luisa Conti ${ }^{8}$ | Iwona Dullinger ${ }^{5,9}$ | Tamara Münkemüller $^{1}$ | Wilfried Thuiller ${ }^{1}$

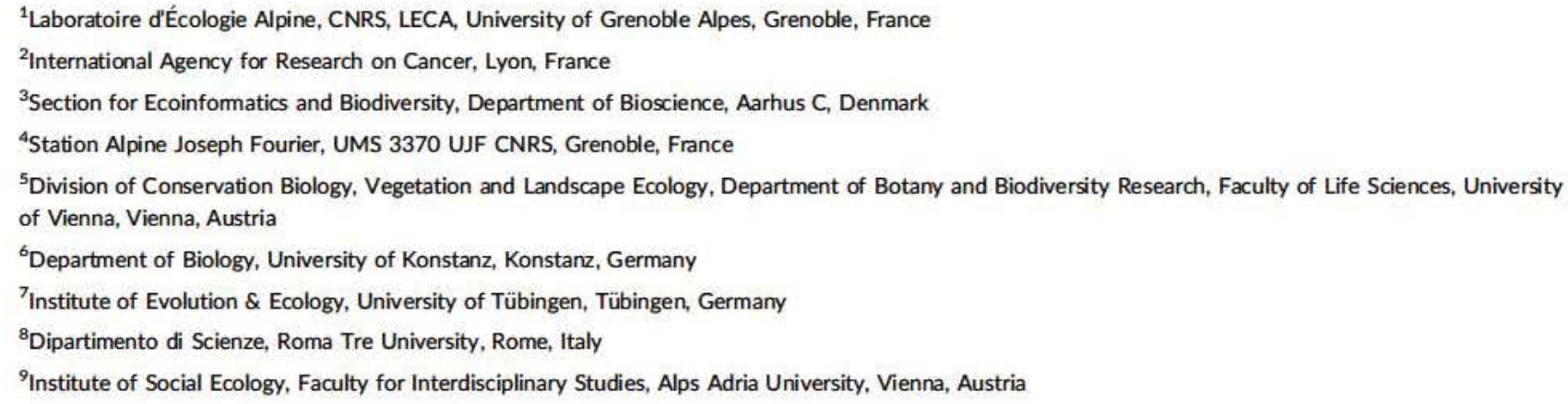

\section{Correspondence}

Marta Carboni, Laboratoire d'Écologie Alpine, CNRS, LECA, University of Grenoble Alpes, Grenoble, France.

Email: marta.carboni@gmx.net

\section{Funding information}

FP7 People: Marie Curie Actions, Grant/ Award Number: FP7 PEOPLE 2012 IEF; IASIMOV 327616; ERA Net BiodivERsA, Grant/Award Number: project "Who Is Next" I 1443 B25; Marie Curie Intra European Fellowship within the European Commission's Seventh Framework Program, Grant/Award Number: FP7 PEOPLE 2012 IEF, IASIMOV 327616; ANR, Grant/Award Number: ANR 11 INBS 0001AnaEE Services

\begin{abstract}
Across the globe, invasive alien species cause severe environmental changes, altering species composition and ecosystem functions. So far, mountain areas have mostly been spared from large-scale invasions. However, climate change, land-use abandonment, the development of tourism and the increasing ornamental trade will weaken the barriers to invasions in these systems. Understanding how alien species will react and how native communities will influence their success is thus of prime importance in a management perspective. Here, we used a spatially and temporally explicit simulation model to forecast invasion risks in a protected mountain area in the French Alps under future conditions. We combined scenarios of climate change, land-use abandonment and tourism-linked increases in propagule pressure to test if the spread of alien species in the region will increase in the future. We modelled already naturalized alien species and new ornamental plants, accounting for interactions among global change components, and also competition with the native vegetation. Our results show that propagule pressure and climate change will interact to increase overall species richness of both naturalized aliens and new ornamentals, as well as their upper elevational limits and regional range-sizes. Under climate change, woody aliens are predicted to more than double in range-size and herbaceous species to occupy up to $20 \%$ of the park area. In contrast, land-use abandonment will open new invasion opportunities for woody aliens, but decrease invasion probability
\end{abstract}


for naturalized and ornamental alien herbs as a consequence of colonization by native trees. This emphasizes the importance of interactions with the native vegetation either for facilitating or potentially for curbing invasions. Overall, our work highlights an additional and previously underestimated threat for the fragile mountain flora of the Alps already facing climate changes, land-use transformations and overexploitation by tourism.

\section{KEYWORDS}

alien species, biotic interactions, dynamic vegetation model, European Alps, mountain

environments, omamental species, propagule pressure

\section{1 | INTRODUCTION}

Despite the recognized and growing problem of invasive alien species damaging native diversity and ecosystem function (Mack et al., 2000; Sax \& Gaines, 2008), it is clear that not all habitats are equally susceptible to invasion by species introduced through human intervention (Chytrý et al., 2008). Mountain ecosystems, for example, have largely been spared from invasions, mostly because of harsh climatic conditions and comparatively low human population densities (Kueffer et al., 2013; Pauchard et al., 2009). However, the diversity and abundance of alien plants in mountain ranges has been increasing over the last few years (Becker, Dietz, Billeter, Buschmann, \& Edwards, 2005; Johnston \& Pickering, 2001; Pauchard et al., 2009; Pickering, Hill, \& Green, 2008), suggesting that the potential for invasion impacts to increase in the future already exists (Williamson \& Fitter, 1996).

Alpine environments in Europe are increasingly threatened by climate change (Engler et al., 2011), abandonment of traditional agro-pastoral practices leading to shrub and tree encroachment (Gehrig-Fasel, Guisan, \& Zimmermann, 2007) and the development of mountain areas for recreational use (Godde, Price, \& Zimmerman, 2000). In the future, these three aspects of environmental change are likely to interact with biological invasions and with the potential for native vegetation to resist such invasions. A warming climate is likely to weaken some of the barriers currently constraining aliens to lower elevations (Petitpierre et al., 2016). The effects of land-use abandonment on the future spread of alien species are more difficult to predict as abandonment could either open new opportunities for the invasion of alien trees and shrubs or, in contrast, lead to greater biotic resistance of the resident vegetation following woody species encroachment (Lenda et al., 2012; Pruchniewicz, 2017). Increased tourism and growing human populations will inevitably lead to higher colonization and propagule pressures of alien species, which is known to enhance their spread (Colautti, Grigorovich, \& Maclsaac, 2007; Kalwij, Robertson, \& van Rensburg, 2008; Lockwood, Cassey, \& Blackburn, 2009). Finally, given that ornamental horticulture is the major introduction pathway for invasive plants (Weber, 2005), new alien invasions in mountains could be fostered through the introduction of preadapted ornamental species for revegetation of disturbed sites or as amenity plantings in resorts (Kueffer et al., 2013; McDougall, Morgan, Walsh, \& Williams, 2005).

Preventing biological invasions is much more time- and costefficient for conservation management than control and eradication efforts following introduction (Leung et al. 2002). However, although researchers are increasingly acknowledging the growing importance of biological invasions as a threat in mountain areas (Kueffer et al., 2013; Pauchard et al., 2009, 2016), scenario-based assessments of plant invasion risks, and particularly those that account for the effects of different drivers of invasion, are largely missing (but see Petitpierre et al., 2016). Modelling alien species spread does pose several challenges (Gallien, Munkemuller, Albert, Boulangeat, \& Thuiller, 2010). For example, given that alien species interact with natives, it is critical to account for native vegetation changes under global change (Pauchard et al., 2016). Furthermore, because invading alien species are typically not at equilibrium, the dynamics of dispersal and spread must be taken into account (Gallien et al., 2010; Theoharides \& Dukes, 2007). Finally, as different global change components such as climate, land-use and propagule pressure have so far been mostly studied in isolation, we still poorly understand their interactive effects (Bradley, Blumenthal, Wilcove, \& Ziska, 2010; Nobis, Jaeger, \& Zimmermann, 2009). Hybrid dynamic vegetation models integrate the advantages of phenomenological environmental suitability models and of processbased models, and can therefore address all of the challenges described above (Dormann et al., 2012). They thus represent an excellent tool for investigating alien species expansion in mountain regions under global change (Boulangeat, Georges, \& Thuiller, 2014; Bradley et al., 2010; Gallien et al., 2010).

In this paper, we use the hybrid simulation model FATE-HD to predict invasion risks (i.e. the likelihood of invasion) in a protected mountain area in the French Alps under different scenarios of future climate, land-use and propagule pressure. More specifically, we ask (1) whether increased propagule pressure, climate change, land-use abandonment and their interactions will lead to greater plant invasion risks in mountain ecosystems, and (2) whether the escape and spread of preadapted plants introduced through omamental trade will present an additional risk under these scenarios. 


\section{2 | MATERIALS AND METHODS}

\section{1 | Study area}

We focused on a protected mountain area in the French Alps (Ecrins National Park ENP), which covers 270,000 ha and is characterized by large environmental and altitudinal gradients (650 4,100 m a.s.l.), with lower altitudes mostly at the peripheries of the park (Fig. S1). The ENP is located at the crossroads of temperate and Mediterranean climates and harbours ca. 2,000 vascular plant species, with so far only very few occurrences of alien species. Currently, twothirds of the park consist of open habitats, managed mostly through traditional agro-pastoral practices such as extensive grazing (80\%) and/or mowing (25\%), while forests cover ca. $25 \%$ of the area. The department Hautes-Alpes (where the ENP is located) is currently the third least populated in France, but since 2006 its population has increased by ca. $1.2 \%$ each year, more than twice the national average (Insee, 2014), supporting more than 360,000 tourist beds. Within the department, the ENP is in itself a tourist destination, supported by a network of $740 \mathrm{~km}$ of mountain trails and more than 30 mountain huts.

\section{2 | Hybrid simulation model}

We used the spatially explicit hybrid model FATE-HD to simulate spatio-temporal dynamics of resident vegetation and plant invasions under different global change scenarios (Boulangeat, Georges, et al., 2014; Boulangeat, Georges, Dentant, et al., 2014). FATE-HD combines species distribution models (SDMs) with process-based modelling to simulate population dynamics (dispersal, germination, recruitment, survival and seed production) of species or plant functional groups as a function of environmental suitability (with temporal stochasticity), competition for light and species traits. A disturbance submodel allows the simulation of management practices by including spatially explicit and species-specific mortality in relation to grazing and mowing.

The FATE-HD model was recently parameterized for the ENP and used for simulating the dynamics of 24 plant functional groups (PFGs) at $100 \mathrm{~m}$ resolution (Boulangeat, Georges, et al., 2014; Appendix S1). Using PFGs, i.e. clustering species with similar characteristics that respond to biotic and abiotic constraints in a similar way, was required to increase computing speed. The PFGs for the dominant native species in the park were constructed using a clustering approach (Boulangeat et al., 2012) based on environmental preferences and five functional traits related to the processes implemented in FATE-HD (tolerance to shading, vegetative height, dispersal distance class, tolerance to grazing and life form). Environmental suitability maps for each PFG were created through species distribution models (SDMs) with the ensemble modelling platform biomod2 (Thuiller, Lafourcade, Engler, \& Araujo, 2009), by pooling occurrences of the representative species in the French Alps and relating them to seven topo-climatic variables (slope, percentage of calcareous soil and five bioclimatic variables). Mowing and three intensities of grazing were simulated annually based on a map of the currently managed areas in the ENP (Esterni et al., 2006). Through this approach, Boulangeat, Georges, et al., (2014) were able to successfully reconstruct and validate the current distribution and structure of the native vegetation in the park. Here, we used this model and its output as a baseline for simulating introductions of alien species. For a more detailed description of the base model, parameterization and databases used see Appendix S1, and for a full description see Boulangeat, Georges, et al., (2014).

\subsection{Alien and ornamental species}

In order to simulate potential invasions, in addition to the 24 PFGs of native species already parameterized and simulated in the ENP, we built a set of PFGs of alien species. We focused on two groups of potential future plant invaders for the park: 1) the most abundant alien species currently naturalized in the surrounding French Alps and 2) a set of mountain-adapted species from a pool of candidate ornamental species that have been shown to harbour potential for future invasions in Europe (Dullinger et al., 2016). First, we identified the alien species already naturalized in the region using a vegetation database provided by the National Alpine Botanical Conservatory (CBNA) for the French Alps (Fig. S1a). This database provides broad coverage for the French Alps, with more than 40,000 total recorded occurrences for alien species. We selected alien species recorded in at least 100 plots in the French Alps and occurring at least once within the ENP. This left us with a set of 40 current alien invaders in the region ("naturalized aliens" hereafter). Second, for the set of ornamental species, we based our selection on the species identified by Dullinger et al. (2016) as potential future ornamental escapes in Europe. These are all nonnative ornamental plants currently cultivated or commercially available in Europe, known to have already naturalized in the wild outside Europe, and predicted to be favoured under climate change in Europe. We narrowed this candidate species group based on availability of trait data, and by identifying, through a search on efloras.org, those species reported to occur in alpine environments in their native or naturalized ranges. As a result, we ended up with 10 candidate herbaceous ornamental species not yet naturalized in Europe but with high potential of escaping in the ENP ("ornamentals" hereafter).

We used the same approach previously adopted for the native species (outlined in detail in Boulangeat et al., 2012) to build and parameterize functional groups of naturalized alien and ornamental species (Appendix S3); here, however, we opted for creating groups of relatively few species as the starting species pool was more functionally diverse. Demographic factors for parameterization (longevity and age at maturity) and most functional trait values (tolerance to shade, vegetative height, dispersal distance class and tolerance to grazing) were derived from the literature (Kattge et al., 2011; Landolt et al., 2010) and/or from expert assessment (see Appendices S1, S3). For the ornamental species (for which many trait values were not available through databases or expert knowledge), we used data from experiments with the same set of ornamental species: a 
shading experiment to judge species tolerance to shade (Haeuser, Dawson \& van Kleunen, unpublished data) and a competition experiment across different watering treatments to measure height (Conti et al. submitted). In the end, the functional group classification identified 18 functionally homogenous alien species groups (Table 1, Appendix S3): 13 PFGs for the naturalized aliens (four phanerophytes, ' $\mathrm{P}$ ', one chamaephyte, ' $\mathrm{C}$ ', eight herbaceous, ' $\mathrm{H}$ ') and five PFGs for the ornamentals (one chamaephyte and four herbaceous).

For each alien PFG, we produced environmental suitability maps through the ensemble modelling platform biomod2 (Thuiller et al., 2009), by pooling occurrences of the associated species. For the "naturalized alien" group, we used exactly the same approach as for the natives and based the SDMs on environmental and occurrence data (presence and absence) from the CBNA in the entire French Alps (using the same variable set as for the natives), in order to account for the realized niche in the adventive range in the study region. This approach has been shown to provide equal performance for predicting potential presences of alien species in the French Alps

TABLE 1 Alien plant functional groups (PFGs) with examples of species for naturalized aliens (aH1-8, $\mathrm{aC} 1$ and $\mathrm{aP1}-4)$ and ornamentals (oH1-4, oC1). Life form classes are herbaceous (aH1-8, oH1-4), chamaephytes (aC1, oC1) and phanerophytes (aP1-4)

\begin{tabular}{|c|c|}
\hline PFG & Species \\
\hline \multicolumn{2}{|c|}{ Naturalized Aliens } \\
\hline $\mathrm{aC} 1$ & Senecio inaequidens \\
\hline $\mathrm{aH} 1$ & $\begin{array}{l}\text { Amaranthus albus, Amaranthus hybridus, Amaranthus } \\
\text { retroflexus, Panicum capillare }\end{array}$ \\
\hline $\mathrm{aH} 2$ & $\begin{array}{l}\text { Ambrosia artemisiifolia, Bunias orientalis, Euphorbia lathyris, } \\
\text { Juncus tenuis }\end{array}$ \\
\hline $\mathrm{aH} 3$ & $\begin{array}{l}\text { Artemisia annua, Euphorbia maculata, Datura stramonium, } \\
\text { Tragus racemosus }\end{array}$ \\
\hline $\mathrm{aH} 4$ & $\begin{array}{l}\text { Bidens frondosa, Conyza sumatrensis, Arundo donax, } \\
\text { Sorghum halepense }\end{array}$ \\
\hline $\mathrm{aH} 5$ & $\begin{array}{l}\text { Conyza canadensis, Solidago canadensis, Solidago gigantea, } \\
\text { Oenothera biennis, Oenothera glazioviana }\end{array}$ \\
\hline $\mathrm{aH} 6$ & $\begin{array}{l}\text { Erigeron annuus, Impatiens balfouri, Impatiens glandulifera, } \\
\text { Galega officinalis, Oxalis fontana, Bromus catharticus, } \\
\text { Panicum dichotomiflorum }\end{array}$ \\
\hline $\mathrm{aH} 7$ & $\begin{array}{l}\text { Phytolacca americana, Reynoutria japonica, Reynoutria } \\
\text { sachalinensis }\end{array}$ \\
\hline $\mathrm{aH} 8$ & Sporobolus vaginiflorus \\
\hline aP1 & Buddleja davidii, Robinia pseudoacacia, Syringa vulgaris \\
\hline aP2 & Pyracantha coccinea, Parthenocissus inserta \\
\hline aP3 & Ailanthus altissima \\
\hline aP4 & Cedrus atlantica \\
\hline \multicolumn{2}{|c|}{ Ornamentals } \\
\hline oC1 & Potentilla argyrophylla \\
\hline $\mathrm{oH} 1$ & Centaurea americana, Centaurea macrocephala, Zinnia peruviana \\
\hline $\mathrm{oH} 2$ & Eritrichium canum, Iris domestica \\
\hline $\mathrm{oH} 3$ & Helenium bigelovii \\
\hline $\mathrm{oH} 4$ & Heliotropium arborescens, Nepeta racemosa, Persicaria capitata \\
\hline
\end{tabular}

as models that contemporarily account for global occurrences (Gallien, Douzet, Pratte, Zimmermann, \& Thuiller, 2012). For the "ornamental" group, this approach was not possible as these species have not yet naturalized in the region. We therefore used the world-wide occurrence data available through Global Biodiversity Information Facility (GBIF; within $10^{\prime} \times 10^{\prime}$ grid cells) as the best available approximation. We acknowledge that this likely represents an overestimation of the realized environmental niche for these species in the ENP region (as shown by Gallien et al., 2012 for the French Alps), but in our approach the environmental suitability only represents the fundamental climatic constraints. The limits imposed by dispersal and biotic interactions are explicitly modelled in FATE-HD and should reduce this bias. As we had no information on true absences of species through GBIF we generated 1,000 'pseudoabsences" outside a radius of $40 \mathrm{~km}$ but no further than $500 \mathrm{~km}$ of each occurrence point (to only include environmental conditions where the species could have potentially dispersed). This selection of pseudo-absences also allows having the same sample bias as the occurrence data, which has been shown to be a good practice in species distribution modelling (Phillips et al., 2009). We used a bioclimatic variable set to span a range of influential temperature and precipitation conditions with negligible multicollinearity effects, obtained from WorldClim (Hijmans, Cameron, Parra, Jones, \& Jarvis, 2005): BIO6 minimum temperature of coldest month, BIO10 mean temperature of warmest quarter, $\mathrm{BIO} 12$ annual precipitation, BIO14 precipitation of driest month. For model details, maps (Fig. S3 S5) and evaluation (Tables S6 and S7) see Appendix S4.

\subsection{Simulation workflow and scenarios}

As a starting point for our simulation workflow, we used the validated simulations of the equilibrium vegetation of the ENP under current climate and land-use management (Boulangeat, Georges, et al., 2014; Boulangeat, Georges, Dentant, et al., 2014). We then simulated the introduction of the alien PFGs through annual seeding. The sites of simulated introduction were based on a map of the Human Footprint in the ENP (Fig. S3 in Appendix S2). The Human Footprint (Sanderson et al., 2002) is an index combining information on land-use, population density and transportation network (including mountain footpaths). As such it represents an excellent proxy of potential local propagule pressure for introduced species (Lockwood, Cassey, \& Blackburn, 2005). Simulations were run for 800 time-steps after starting alien introductions, in order to allow reaching quasiequilibrium and stabilization of the long-lived alien PFGs, as well as for comparability with the natives. Note that there is considerable uncertainty about the temporal scale and resolution of transient dynamics and we have insufficient data for a precise temporal validation. For this reason we focus mostly on equilibrium conditions (as done previously, e.g. Boulangeat, Georges, et al., 2014; Boulangeat, Georges, Dentant, et al., 2014), though we also examine mid-term responses and interpret temporal dynamics in relative terms. Furthermore, to assess the naturalization potential of the alien PFGs in the ENP independently of propagule pressure, in a separate set of 
simulations the yearly introductions were stopped after 300 years. This set of simulations, though unrealistic, also allowed evaluation of potential effects of bans on alien species from park managers. Although alien abundance dropped considerably when stopping introductions, and the effect to each PFG differed in strength, the overall response of the alien species to future global change scenarios was qualitatively very similar in simulations with and without continued introductions (see Appendix S5). In the following, we thus focus on simulations in which introductions were continued throughout.

We simulated two scenarios of propagule pressure (current or increased) depending on the development of tourism, combined with two scenarios of future climate (current climate or climate change) and two land-use scenarios (current land-use or land-use abandonment). In the current propagule pressure scenario, introductions were a proportion of a set maximum number of seeds depending on the human footprint value in each pixel (i.e. highest introduction intensity in the most densely populated centres, and lowest introduction intensity along mountain footpaths; see Appendix S2 for maps and for details). In the increased propagule pressure scenario, the maximum introduction level was applied in all areas that had a non-zero human footprint (simulating a maximum exploitation of all areas suitable to humans). Climate change was simulated by changing habitat suitability maps at 15 years intervals for the first 90 years of simulation, based on climatic projections for the intermediate emissions scenario $\mathrm{A} 1 \mathrm{~B}$, and then held constant for the remaining simulation years to allow vegetation to reach quasi-equilibrium under the target future climate conditions (Appendices S1, S4, Boulangeat, Georges, Dentant, et al., 2014). Land-use abandonment was simulated by stopping all grazing and mowing activities everywhere in the park at year 4 and until the end of the simulation (Boulangeat, Georges, Dentant, et al., 2014). We thus had one baseline scenario in which we simulated the persistence of the current conditions in the ENP (current climate, current management and current human footprint), and several scenarios with combinations of changing conditions. Each alien PFG was introduced in separate simulation runs in order to focus only on biotic interactions with the natives, and each simulation scenario was repeated three times for a total of 432 runs for the set of simulations with continuous introductions (2 PPs * 2 Climate * 2 Land-use $* 18$ PFGs (13 naturalized aliens +5 ornamentals) $* 3$ repetitions).

\section{5 | Analyses}

To answer our first question focusing on naturalized alien PFGs, we analysed different features of alien ranges and abundance that characterize invasion risk under different global change scenarios: (1) the final potential area of occupancy of each naturalized alien PFG in the ENP at equilibrium, (2) the aggregated richness of naturalized aliens in each grid cell $(100 \times 100 \mathrm{~m})$ and $(3)$ the upward shift of the upper altitudinal invasion limit. To assess the final potential area of occupancy of each naturalized alien PFG in the ENP at equilibrium, we calculated the final area of occupancy per PFG as the proportion of grid cells occupied at the end of each simulation run (year 800). We then fit a generalized linear mixed effects model (GLMM) to analyse the response of alien spread to different propagule pressures, land-use regimes and climate scenarios (package 'nlme' in R; Pinheiro, Bates, DebRoy, \& Sarkar, 2007). The response was the final PFG occupancy in the ENP, log-transformed to normalize residuals. We included four fixed factors and all their two-way interactions: "Propagule Pressure" with two levels ("low" and "high"), "Climate" with two levels ("current climate" vs. "climate change"), "LandUse" with two levels ("current land-use" vs. "land-use abandonment") and "Life Form" with three levels (' $C$ ', ' $H$ ' and 'P'). Life form was included because we expect herbaceous, chamaephyte and phanerophyte PFGs to respond differently to global change, which we can assess by examining interaction terms. Finally, we also included PFG identity as a random factor. We consider fixed factors and their interactions to have an effect if the $95 \%$ credible intervals ( $\pm 2 \mathrm{SD}$ ) of the standardized effect sizes do not overlap zero. This model allowed us to assess if the invasion risk in the ENP at equilibrium (i.e. the proportion of the park at risk of being invaded) depends on the global change scenario and on the life form of the alien. To better disentangle the effects of land-use we also calculated and compared PFG occupancy in undisturbed and managed grid cells (mown or grazed) separately. Second, we assessed the aggregated richness of alien species spatially by summing the numbers of alien PFGs predicted to occur in each grid cell. This allowed us to quantify a cumulative invasion risk for each area of the park (but note that this likely represents an upper-bound as interactions among alien species are not accounted for). Finally, we quantified the upper altitudinal invasion limit by calculating the $75^{\text {th }}$ quantile of elevation reached by the alien PFGs. We then assessed the overall dynamics of average aliens' upward spread in time (annual shift of the $75^{\text {th }}$ quantile of elevation) and space (final average number of PFGs at each elevation) across the different scenarios. This allowed us to evaluate invasion risks at higher elevations.

To answer our second question and to test how invasion risk increases as a consequence of the escape and spread of ornamental plants, we followed the same approach outlined above for the naturalized aliens. We assessed the final area of occurrence of each ornamental PFG in the ENP and the aggregated richness of ornamentals in each grid cell at the end of the simulation period. Then, we fit a GLMM relating final occupancy of ornamentals to propagule pressure, land-use, climate, life form and their interactions as fixed factors, including PFG identity as random factor.

\section{3 | RESULTS}

\section{1 | Effects of global change on naturalized aliens}

In the baseline scenario, alien species already naturalized in the French Alps ('naturalized aliens') tended to be relatively uncommon (occupying well below $10 \%$ of the park surface) and mostly limited to lower elevations at the margins of the ENP (Figures 2 6). The relatively tall and shade intolerant herbaceous PFGs $\mathrm{aH} 4$ and $\mathrm{aH} 5$ 
(a)

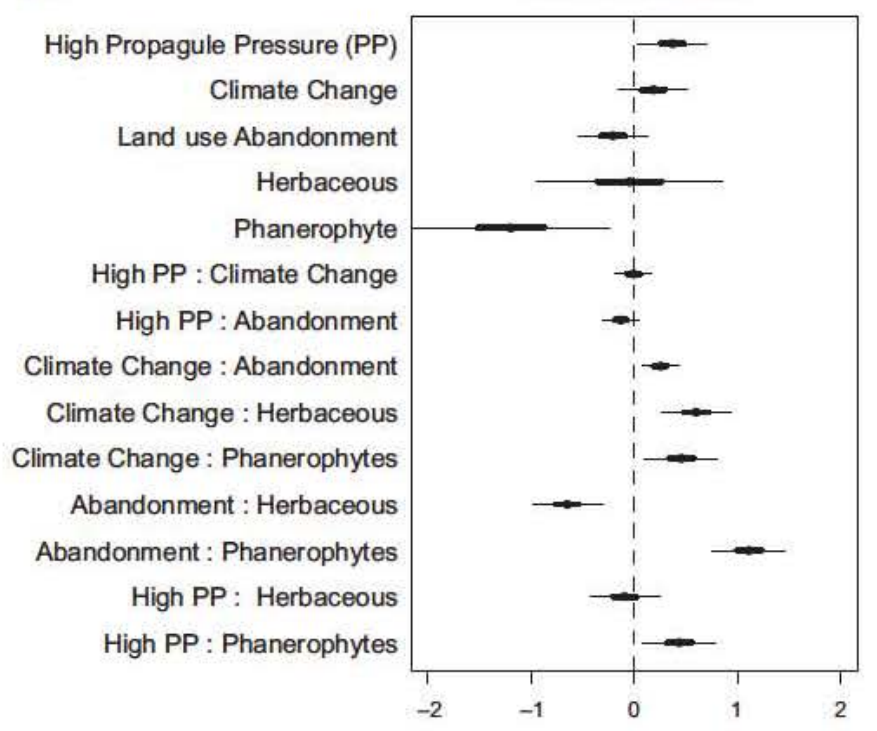

(b)

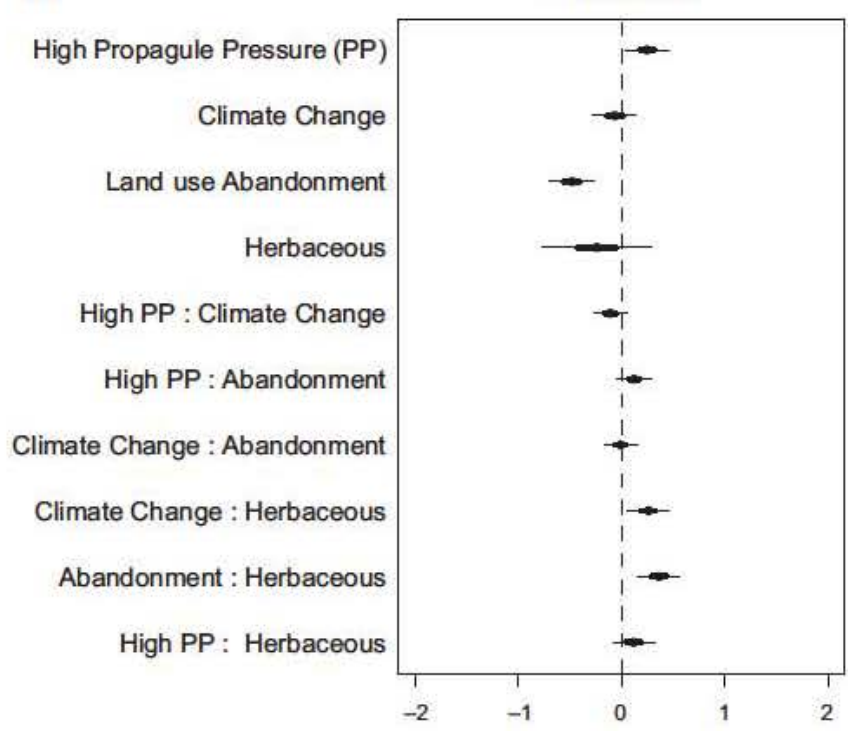

FIGURE 1 Effect sizes for generalized linear mixed effects models (GLMMs) of the response of alien species spread (i.e. final area of occupancy) to different propagule pressure, land-use and climate change scenarios, and their two-way interactions for "naturalized aliens" (a) and "ornamentals" (b). Life form ('Chamephyte', 'Herbaceous' and 'Phanerophyte') was also included as a fixed factor, while plant functional group identity was included as a random factor. Shown are effect sizes \pm 2 SD representing standardized differences compared to the baseline scenario (low propagule pressure, current land-use and current climate) for the chamaephytes
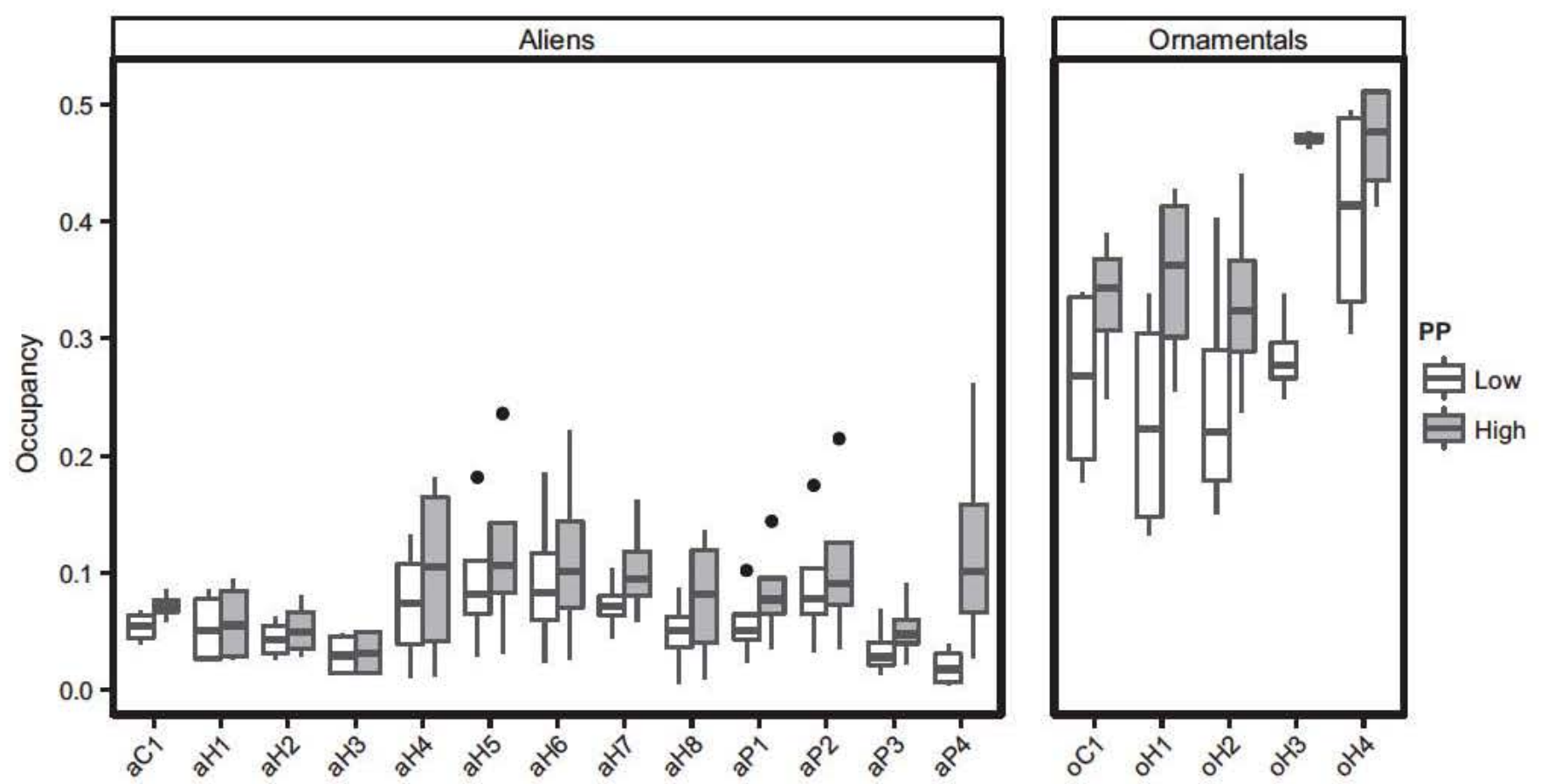

FIGURE 2 Effects of propagule pressure (PP) scenarios on area of occupancy of the alien plant functional groups (PFGs) in the Ecrins National Park at the end of the simulations after reaching quasi-equilibrium. Shown separately are results for already naturalized alien PFGs (left panel) and for omamental PFGs (right panel). See Table 1 for the PFG codes and the species included in each group and Table S5 in Appendix S3 for their parameter values. Refer to Figure 1 for effect sizes for PP across life forms

(including e.g. Conyza and Oenothera spp.) as well as aH6 (including Impatiens spp. and Erigeron annuus) were the most widespread among the herbs, while the shrub group aP2 (e.g. Pyracantha coccinea) characterized by long distance bird-mediated dispersal was the most widespread phanerophyte (Table S5). However, propagule pressure, climate change, land-use abandonment and their interactions all affected invasion success, resulting in significant changes in occupancy within the ENP across PFGs (Figure 1a). The strength of the 



FIGURE 3 Effects of climate change and land-use abandonment scenarios on area of occupancy of alien plant functional groups (PFGs) of different life forms ( $\mathrm{C}$ for chamaephytes, $\mathrm{H}$ for herbaceous and $\mathrm{P}$ for phanerophytes) in the Ecrins National Park at the end of the simulations. The baseline scenario ("Base") represents the persistence of the current conditions in the ENP (current climate and current land-use). Results are shown separately for already naturalized alien PFGs (left panel) and for ornamental PFGs (right panel). Refer to Figure 1 for effect sizes for Climate Change and Abandonment across life forms
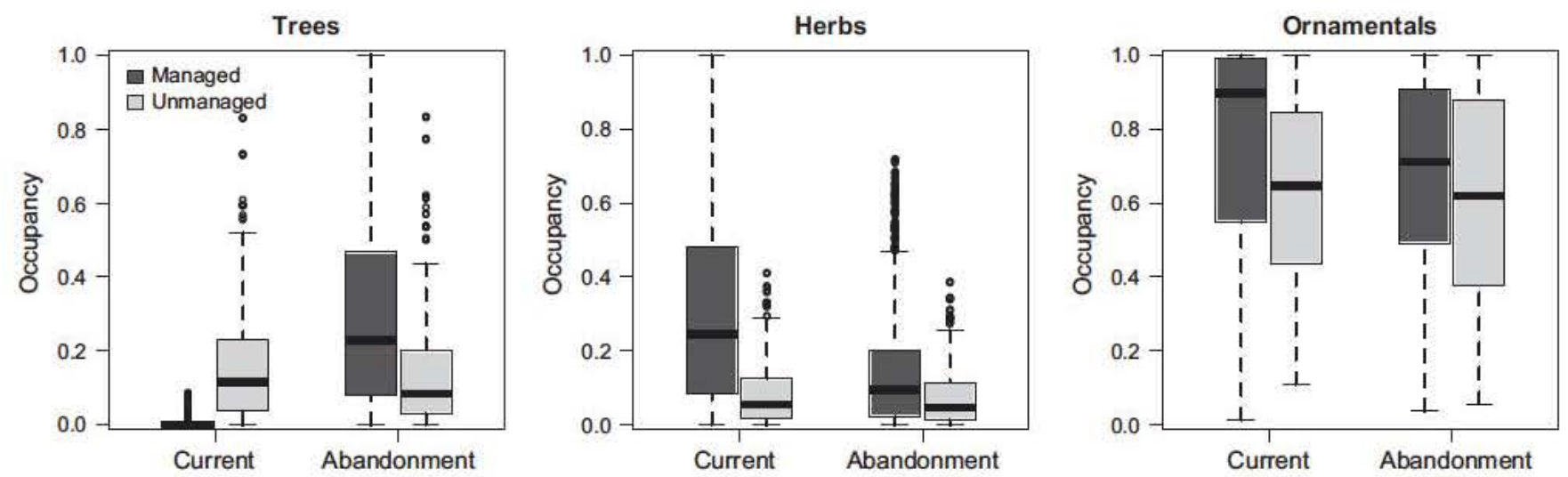

FIGURE 4 Effects of land-use abandonment on area of occupancy of alien plant species of different plant functional groups in the Ecrins National Park at the end of the simulations after reaching quasi-equilibrium. Results are shown separately for managed (grazed or mown) and unmanaged habitats for the naturalized alien trees (i.e. phanerophytes, left), for the naturalized alien herbs (i.e. chamaephytes, and other herbaceous, centre) and for the ornamental functional groups (right)

effects of these global change factors depended on the life form and functional group of the invaders (interaction terms in Figure 1a), as we detail in the following paragraphs.

Increased human-mediated propagule pressure led to greater occupancy for almost all functional groups across scenarios (Figure 2), but certain aliens were particularly affected. Specifically, the long-lived herbaceous (aH7, e.g. Reynoutria japonica) and woody (aP4, Cedrus atlantica) PFGs more than doubled in occupancy in the high propagule pressure scenarios (Figure 2). In accordance with its high dependence on propagule pressure, the occupancy of the $R$. japonica group (aH7) dropped drastically below $1 \%$ of the park area if introductions were stopped after an establishment period (Appendix S6). This was not the case for the phanerophyte $C$. atlantica (aP4), which once established was independent of further introductions and persisted in the study area with similar area of occupancy even in the long term (Appendix S6).
Across propagule pressure scenarios, simulated climate change resulted in significantly greater spread and higher elevation limits for all life forms (Figures 3 and $5 a, b)$, with herbaceous PFGs occupying up to $20 \%$ of the park area and woody PFGs more than doubling in area of occupancy at the end of the simulation time (Figure 3). Herbaceous aliens migrated rapidly upslope following the ongoing climate changes and the upper margin of their ranges stabilized on average $100150 \mathrm{~m}$ higher than in the baseline scenario (Figure $5 \mathrm{c}$ ). The upward shift of alien trees was more modest, not as long-lasting (Figure 5d), and also less pronounced compared to the native trees (Boulangeat, Georges, et al., 2014; Boulangeat, Georges, Dentant, et al., 2014; Fig. S10 in Appendix S6). This pattern was driven mostly by Ailanthus altissima (aP3), which initially migrated upslope but was then likely outcompeted by forest-edge and late-successional native trees (such as nP7 and nP5; Table S1, Fig. S10). Overall, climate change resulted in an increase in the average number of 
(a)

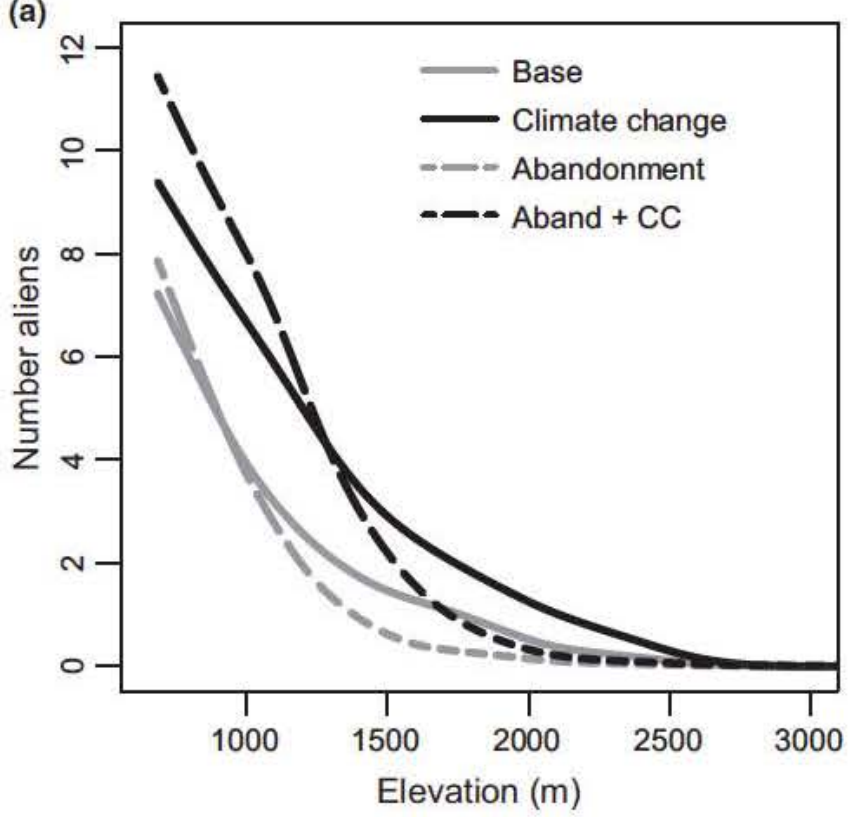

(c)

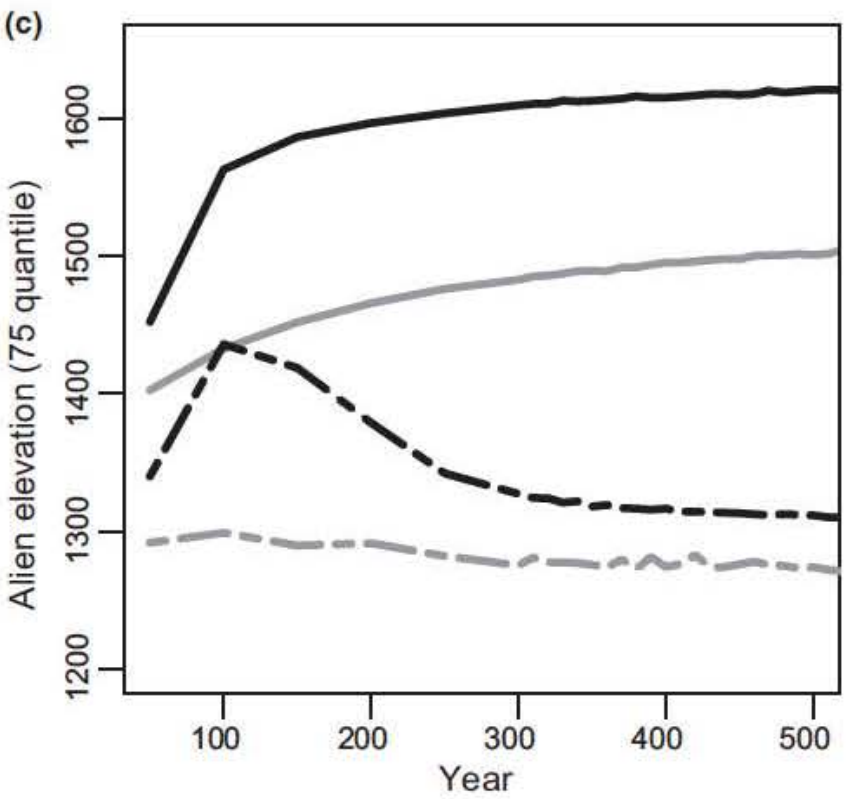

(b)

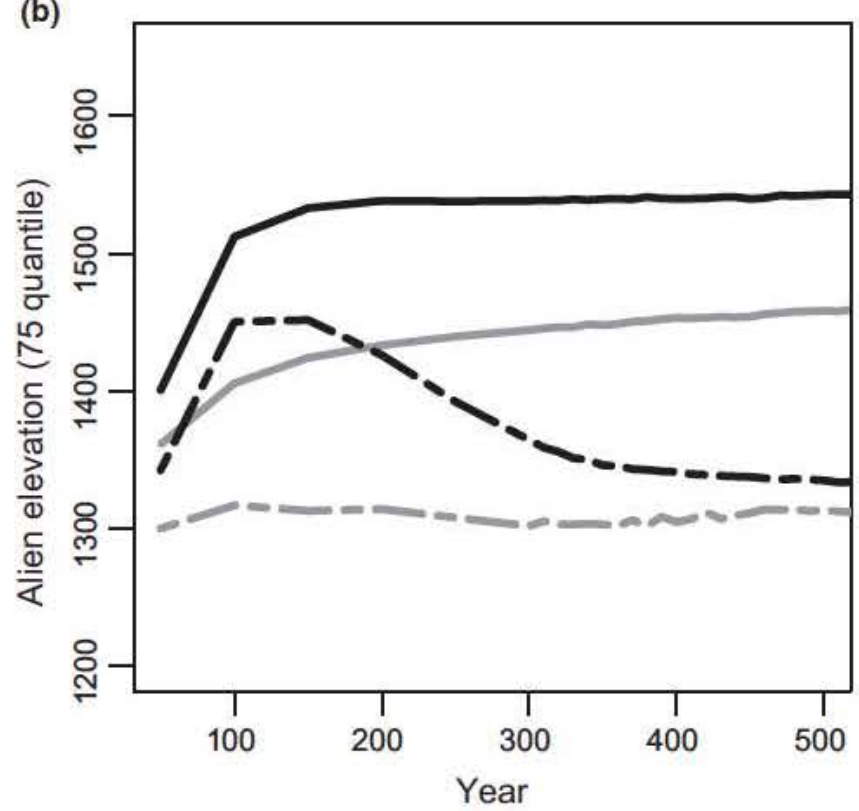

(d)

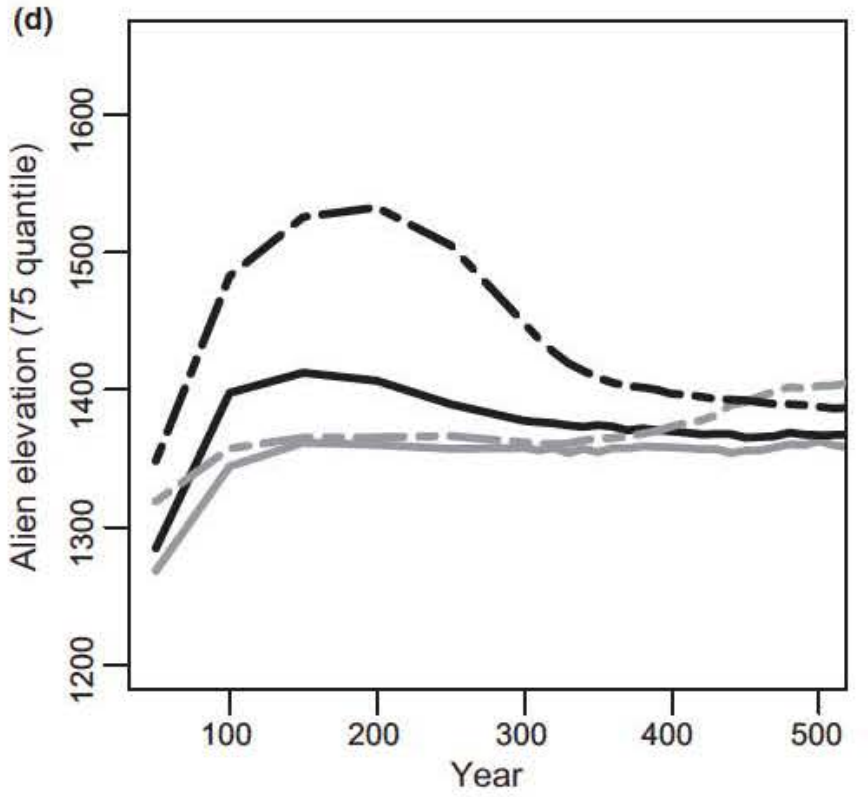

FIGURE 5 Changes in the upper altitudinal invasion limit under different climate and land-use scenarios and under constant (current) propagule pressure shown for one simulation repetition. Shown are the average numbers of naturalized alien functional groups across elevation at the end of the simulation after reaching quasi-equilibrium (a) and the change of the upper quartile of PFG's elevation occurrence for the naturalized aliens (averaged across PFGs) over time for the first 500 years of simulation (b). In panels (c) and (d), the simulated upper elevation dynamics of herbaceous and woody alien PFGs, respectively, are shown. Grey lines represent current climate and black lines climate change scenarios; solid lines represent current land management and dashed lines represent land abandonment scenarios

potentially occurring alien species at all elevations (Figure 5a) and in the interior of the park (Figure 6), and in an upward shift of the invasion front (from ca. 2,000 to 2,500 m a.s.l., Figure 5a).

Land-use abandonment had contrasting effects on herbaceous and woody aliens. On the one hand, abandonment led to a strong decrease in the area occupied by herbaceous aliens (Figure 3) as these were quickly outshaded by native shrubs and trees colonizing the abandoned grasslands (Figure 4). Alien herbs therefore attained much lower elevations in general (Figure $5 c$ ), resulting in lower potential alien richness at all elevations other than in the lowlands below $1,000 \mathrm{~m}$ a.s.l. (Figure $5 \mathrm{a}$ ) and in the periphery of the park (Figure 6). On the other hand, woody aliens profited, just like native shrubs and trees, from abandonment, invading the previously managed areas and expanding their area of occupancy more than under climate change (Figures 3 and 4). This resulted also in an upward shift in the invasion front of woody aliens driven again mostly by $A$. altissima gradually replacing the native pioneer groups after an initial time lag (e.g. the native Larix decidua, nP4; Figs. S9 and S10). As 


\section{Current}

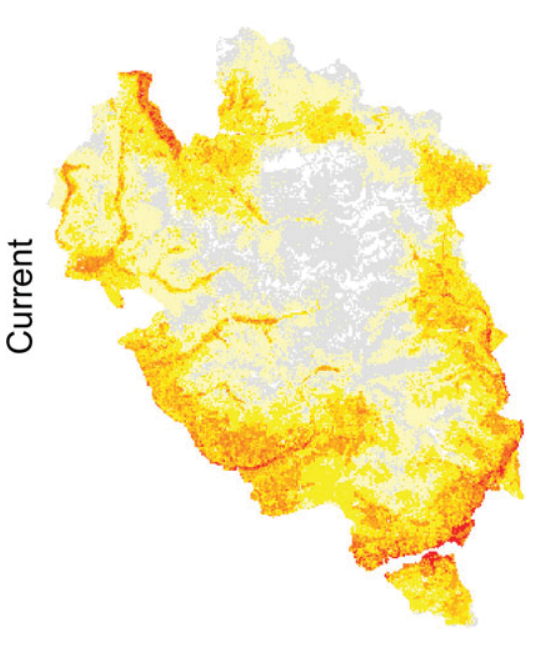

FIGURE 6 Number of alien plant functional groups (naturalized aliens and ornamentals combined) predicted to occur across the Ecrins National Park at the end of the simulation (shown for one repetition), after reaching quasi-equilibrium under different combinations of climate (current or climate change) and land-use scenarios (current or abandonment). The baseline scenario represents the persistence of the current conditions in the ENP (current climate and current land-use under current propagule pressure). See Fig. S11 for patterns at intermediate timeframes. Refer to the online version of this article for a colour-coded scale [Color figure can be viewed at wileyonlinelibrary.com]
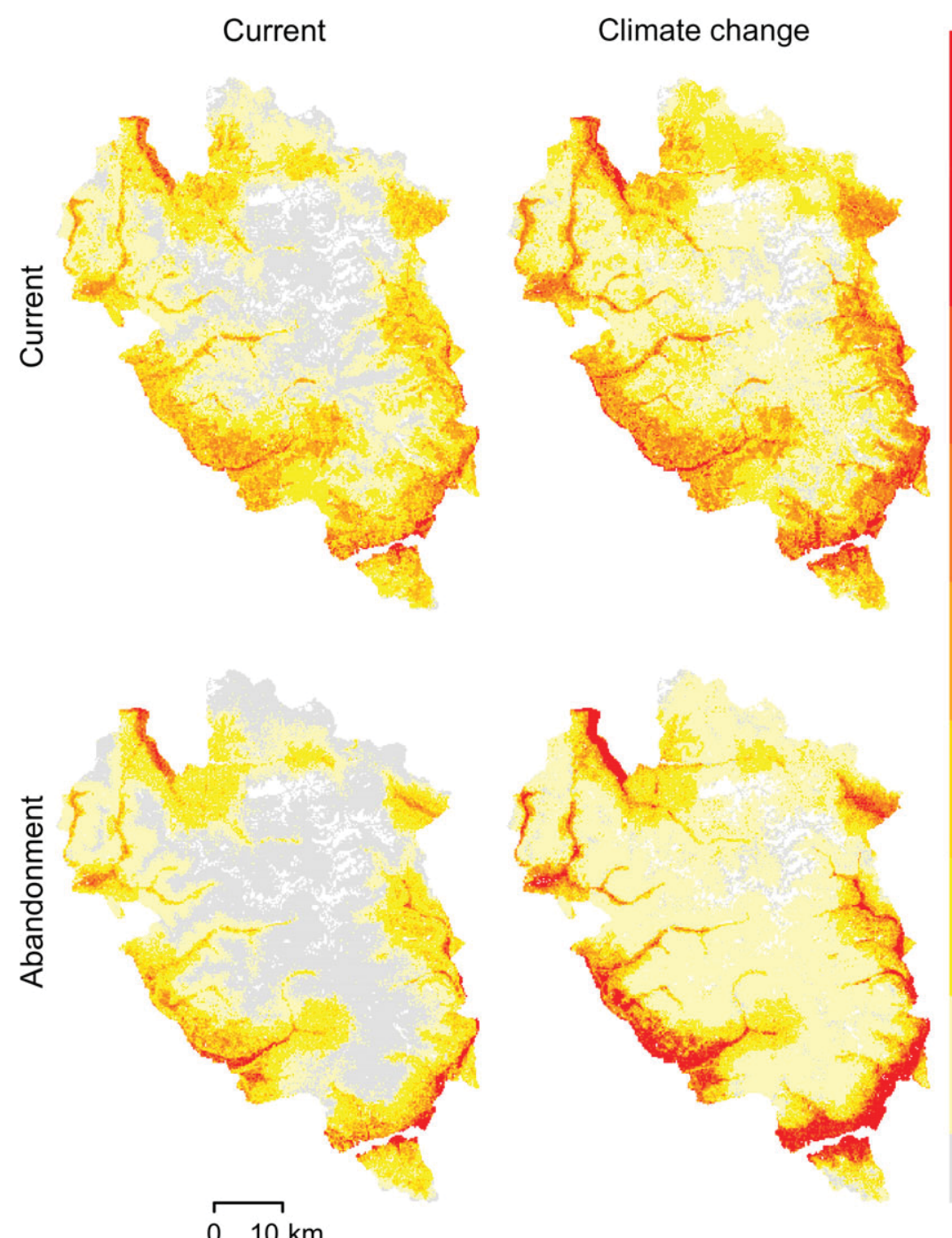

16

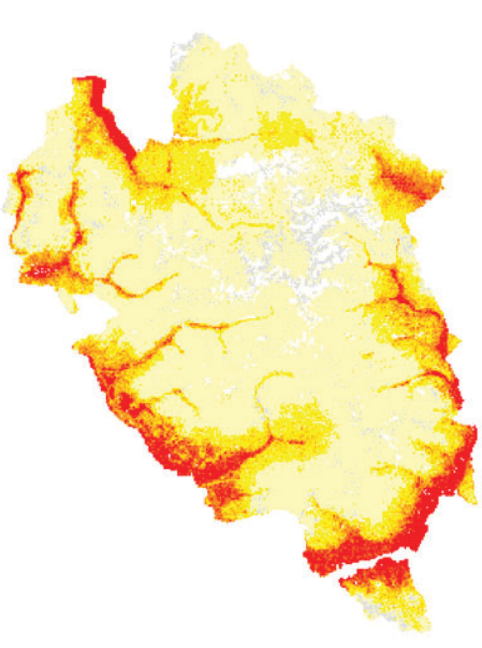

expected, invasion of unmanaged areas was not strongly affected by abandonment (for neither herbs nor trees, Figure 4).

Overall, climate change and land-use abandonment had mostly additive effects on final alien occupancy (Figure 3). These were antagonistic for the herbs and synergistic for the trees. Thus, on the one hand, the occupancy of alien herbs under land-use abandonment combined with climate change was intermediate compared to the scenario with land-use abandonment under current climate and the scenario with climate change under current management (Figure 3). On the other hand, the combined effects of climate change and land-use abandonment resulted in a fourfold increase in the average area of occupancy of the woody PFGs at the end of the simulation (Figure 3). In the scenario in which both climate change and land-use abandonment took place, aliens (including trees such as A. altissima in aP3 and Robinia pseudoacacia in aP1) initially colonized higher elevations following climate change, but were later gradually replaced at the upper limits of their elevation range as native tree cover fully developed after ca. 200300 years (Figs. S9 and S10). At the end of the simulation, this resulted in higher potential local richness of aliens mostly below $1,500 \mathrm{~m}$ and at the borders of the park, but lower average richness than under current management at higher altitudes (Figures 5 and 6).

\section{2 | Ornamental species}

Simulations for ornamental PFGs generally resulted in greater occupancy than for naturalized aliens across simulations, with on average ca. $30 \%$ of the park area being suitable for ornamental establishment in the baseline scenario. In general, all ornamental PFGs were also strongly affected by propagule pressure (Figure 1), with the group $\mathrm{oH} 3$ of Helenium bigevolii (characterized by high environmental suitability at higher elevations, Figs. S1, S5) roughly doubling in abundance in the high propagule pressure scenario (Figure 2). Overall, herbaceous ornamentals responded to other global change components in a qualitatively similar way as the herbaceous naturalized aliens. Climate change mostly led to an increase at higher elevations, while land abandonment resulted in a decrease in the area occupied by ornamentals (Figure 3, Figs. S1b, S12). However, responses varied across the different ornamental groups, which were in some cases limited by climate change as they tracked their suitable climate 
upward in elevation (e.g. see the chamephyte group of Potentilla argyrophylla in Figure 3 or climate suitability evolution for $\mathrm{oH} 4$ in Fig. S6c). In combination, climate change and land abandonment had mostly antagonistic effects, with grid cells becoming suitable for a larger number of ornamentals mostly located in the peripheral lower altitudes of the park (Figs 3, S1b, S12). Interestingly, in the land-use abandonment scenarios ornamental plants were less affected by colonizing native trees within abandoned grasslands compared to herbaceous naturalized aliens (Figure 4).

\section{4 | DISCUSSION}

Mountain ecosystems typically host few alien species, but this situation is rapidly changing with increasing global change (Alexander et al., 2016). Here, we assessed the future potential distribution of a selection of alien plant species in a protected mountainous area in the European Alps, and showed that predicted future global and local changes are likely to relax many of the constraints that currently limit plant invasions to lower altitudes. Our spatially and temporally explicit vegetation model predicts an expansion and often a shift of the upper elevational distribution limit for most modelled alien plant groups under different climate and land-use scenarios. These results highlight an additional and previously underestimated threat for the fragile mountain flora of the Alps, already facing climate changes, land-use transformations and increased tourism.

\subsection{Mountain invasions under global change scenarios}

Our baseline scenario confirmed that mountain ecosystems in the French Alps are currently characterized by limited suitability for alien species, which are largely restricted to lower altitudes in valleys. Indeed, most previous studies from different biomes around the world show a consistent pattern of declining alien plant richness from a maximum at the lowest or lower third of the elevation gradient (Alexander et al., 2011; Pauchard et al., 2009; Seipel et al., 2012). Interestingly, in our simulated baseline scenario, we found declining richness patterns that mirror very closely those observed by Becker et al. (2005) along a similar altitudinal gradient in Switzerland (500 2,500 $\mathrm{m}$ a.s.l.), although in our case we recorded numbers of distinct PFGs rather than species. Compared to previous phenomenological modelling work we obtained less extreme upper elevational limits for our modelled aliens (cfr. Petitpierre et al., 2016). This might be because FATE-HD allows to model two critical processes of species spread, i.e. the demography of metapopulations and the dispersal rate of species, both of which are considered key for expanding invasive species and can limit their potential range (Hastings et al., 2005; Theoharides \& Dukes, 2007; Wilson, Dormontt, Prentis, Lowe, \& Richardson, 2009). We note also that several of the top-10 of the most frequently recorded alien species by Becker et al. (2005) in the Swiss Alps matched the functional groups occupying larger areas in our baseline simulations (Conyza sp. and
Solidago canadensis in aH5, Erigeron annuus and Oxalis fontana in aH6). These congruencies between our baseline simulations and observed patterns in similar environments offer support for our approach. However, in accordance with trends already under way in the European Alps and other mountain ranges (Becker et al., 2005; Johnston \& Pickering, 2001; Pauchard et al., 2009; Pickering et al., 2008), we found an increase in the spread potential of alien species under most future scenarios.

We found strong effects of climate change on invasion risk in the ENP, leading to greater alien occupancy in valleys in the interior of the protected area. A recent study already showed that under a warmer and drier climate, most plant invaders currently naturalized in the surrounding lowlands will strongly gain climatically suitable area in the European Alps (Petitpierre et al., 2016). However, shifts in the native vegetation driven by climate change may potentially limit alien species spread, or alternatively these shifts could further facilitate alien spread (Pauchard et al., 2009). Here, we improve on previous work by accounting for light-mediated interactions with the concurrently shifting native vegetation. While, to a large degree, we corroborate previous results by finding that herbaceous alien species track their climatic niche upslope, we also found evidence that biotic resistance can partially mitigate the upward spread of alien trees such as A. altissima or R. pseudoacacia as a consequence of native woody species encroachment and vegetation succession. These results highlight the importance of accounting for changing biotic interactions.

In addition to climate change, we simulated the two main trends in the future anthropogenic development of European mountain landscapes: abandonment of pastoral activities vs. the development of tourism. Both significantly affected the future risk of plant invasions in the ENP. Higher propagule pressure, associated with the development of tourism in mountains, increased the area potentially invaded by alien species, a pattern reinforced under climate change in accordance with previous results (Nobis et al., 2009). While propagule pressure increased the risk of invasion across all modelled functional groups, the abandonment of grazing and mowing had more complex effects. Abandonment opened new invasion opportunities only for woody alien groups, leading to increases comparable to those associated with climate change in terms of final occupancy and upslope shift, though after a considerable time lag (ca. 300 years). Indeed, lagged spreads of certain trees such as Robinia pseudoacacia and Ailanthus altissima into natural environments after more than a century of planting into public parks are known from Central Europe, potentially also in response to warming climates and the availability of more suitable sites (Kowarik, 1995). In contrast, we found opposite patterns for herbs. Herbaceous alien species are known to profit from anthropogenic disturbances, particularly in cold climates such as high elevation habitats (Eskelinen, Kaarlejarvi, \& Olofsson, 2017; Vavra, Parks, \& Wisdom, 2007). When such grazing and mowing disturbances were eliminated in our simulations, we observed strong declines in the spread of alien herbs, as a consequence of colonization by native trees that outshaded them. Such declines after abandonment were consistent among all herbaceous 
aliens groups, while herbaceous natives had more mixed responses depending on their shade tolerance (Boulangeat, Georges, et al., 2014).

Climate changes and land-use abandonment also interacted in a complex fashion by influencing the transient dynamics of alien species spread in the ENP. Aliens profited from the slow growth, long life cycles and consequently slow recolonization of native plants (Dullinger, Dirnbock, \& Grabherr, 2004; Pauchard et al., 2009) and thus temporarily spread upslope, tracking the gradually more suitable climate in the first 200 years of simulation. These results suggest that even if the responding native vegetation may eventually exclude aliens at higher altitudes, interacting climate and land-use changes may offer a window of temporary invasion in the short to mid-term. Indeed at year 100, which represents a mid-term time-frame which is relevant for conservation, invasion risk and richness of aliens across the park was higher for almost all scenarios (Fig. S11, year 100). We note that the later exclusion of aliens depends on our parameterization assumption that allows germination and recruitment in shady conditions for woody native species (Boulangeat, Georges, et al., 2014). Lastly, in the long run, the interaction of landuse abandonment with climate change at equilibrium also shifted the areas of highest invasion risk spatially, restricting the areas suitable for the maximum number of aliens to lower altitudes at the periphery of the ENP.

Overall, we showed that interacting agents of global change in combination with the responses of the native vegetation can have unforeseen effects on both the temporal dynamics and final distributions of alien plants in mountains. By accounting jointly for several main agents of anthropogenic environmental change, we illustrate invasion opportunities driven by the interactions between climate change and other human-caused changes (i.e. land-use abandonment and increased propagule pressure). Our results also highlight the importance of accounting for often-neglected biotic interactions with the resident vegetation, including the potential facilitating effects of range-expanding natives and the relaxation of biotic resistance from declining alpine species.

Finally, preadaptation to severe abiotic conditions might promote future invasions of newly introduced ornamental plants into touristically developing mountains (Kueffer et al., 2013; McDougall et al., 2005; Pauchard et al., 2009). We tested this idea in the ENP for a set of functional groups of ornamental plants that already have a naturalization history in high altitudes of other mountain ranges. Our simulations showed that, if introduced, large areas of the ENP would be suitable for the establishment of these alien ornamentals under different future scenarios. Although we cannot quantitatively compare the final area of occupancy of these ornamental species to that of the already naturalized aliens because of differences in the underlying environmental suitability models, the qualitative response to global change agents was informative. For example, we found that preadapted ornamental species were very strongly favoured by increased propagule pressure at higher elevations (strong propagule pressure effect, Figures 1 and 2). This effect was on average less strong for the already naturalized aliens (Figure 2). Because most alien species to date have been initially introduced into lowland habitats, there may be selection against taxa adapted to higher elevations (Becker et al., 2005; Marini et al., 2013). In our future scenario in which preadapted aliens were introduced directly into higher elevations because of increased propagule pressure, this "lowland filter" was reduced and invasion risks became much higher than under current introduction scenarios (e.g. oH3, Helenium bigelovii). Furthermore, while herbaceous ornamental plants and already naturalized aliens generally responded to climate and management change in a similar way, the ornamentals were less affected by developing forest cover in abandoned pastures. This was because they were on average more tolerant to shade and to competition (i.e. had higher survival rates and recruitment in highly shaded/competitive environments). This result suggests that traits that might typically be selected for in the horticultural trade for alpine gardens (e.g. fast growth under limited resources, winter hardiness) might provide a competitive advantage for ornamental plants escaping into mountain landscapes under future land-use transformations (Marco, Lavergne, Dutoit, \& Bertaudiere-Montes, 2010; Maurel, Hanspach, Kuhn, Pyšek, \& van Kleunen, 2016; Van Kleunen \& Johnson, 2007). Overall, by relying on both functional traits and climatic envelopes from global ranges, we could provide first estimates of suitability of a European mountain region for alien ornamental plants that have not yet escaped cultivation, as well as their responses to future global change agents. Although these insights are certainly still approximations, they provide a basis for putting in place proactive alien species management in mountain environments.

\subsection{Threat to native mountain flora and management responses}

Mountainous environments are assumed to be threatened by a suite of ongoing environmental changes, but biological invasions are considered to be of less relevance (Sala et al., 2000). We have shown that global change factors will reduce the potential of native vegetation in mountains to resist invasion, and that it is a matter of time before alien species will spread to higher elevations. Given that the flora of mountains is particularly vulnerable to rapid environmental changes due to dispersal-limiting rugged mountain morphology and the presence of many range-restricted species (Engler et al., 2011; Thuiller et al., 2014), the additional pressure caused by increased biological invasions may have serious long-term consequences for mountain biota.

Contrary to many already highly invaded ecosystems, science and management still have the opportunity to act precautionarily in mountain environments. Limiting the spread of existing alien species populations along elevational gradients is an important initial management goal (Lembrechts et al., 2017). We have shown that if introductions are limited or completely stopped, e.g. through appropriate regulations drastically curbing propagule pressure, some alien functional groups, such as Ambrosia artemisiifolia or Reynoutria japonica, which are highly invasive in other settings, would very quickly be excluded in these harsh environments under most future 
scenarios. However, this was not the case for many other groups (e.g. Cedrus atlantica), highlighting the importance of cost-effective early management response. One essential tool for precluding future invasions is the close control and regulation of preadapted ornamental plants in new ski or mountain resorts for amenity plantings or revegetation (McDougall et al., 2005). Examples of available policy instruments that tackle invasions at different stages of the horticulture supply-chain include preborder import restrictions at a national level for the species most at risk of spreading, postborder bans at a local level within the park, voluntary codes of conduct for mountain nurseries and those of the surrounding areas, and consumer education towards non-invasive functional groups of ornamental plants for mountain gardens and resorts (Hulme et al., 2017). Moreover, management policies directed at conserving native species should contemporarily take into account repercussions on the spread of alien species. For example, Boulangeat, Georges, Dentant, et al., (2014) recommend continued pasturing to maintain native diversity in the ENP. While this policy will also keep in check the expansion of alien trees, it will contemporarily allow greater opportunities for alien herbs. Close monitoring for early screening of alien herbs in the pastured lands should thus go hand in hand with this recommendation.

In conclusion, using the hybrid dynamic model FATE-HD to simulate plant invasions, we predict occupancy expansions for most modelled alien plant species and a shift of the invasion front to higher elevations under most future scenarios in the ENP. Climate change and higher propagule pressures will be the most significant drivers of increasing invasion risk across species. Land-use abandonment in interaction with climate change will open invasion opportunities for alien trees at intermediate time-frames. The introduction of well-adapted ornamental plants will further increase invasion risks in these environments, particularly at higher elevations and under increased propagule pressure. However, the native vegetation responding to global change can partially mitigate more widespread invasions. Our spatially and temporally explicit approach addresses many of the limitations of previous works, highlighting the promise of hybrid models for studying alien species and critically assessing the risk of future invasions into mountain environments. It also opens many perspectives for future developments, including accounting for species-specific introduction pathways of aliens (Wilson et al., 2009) and mutualisms such as animal-mediated dispersal (Traveset \& Richardson, 2014), or modelling additional mechanisms for biotic interactions such as competition for nutrient uptake and multitrophic partners.

\section{ACKNOWLEDGEMENTS}

This research was funded by the ERA-Net BiodivERsA (project "Who Is Next" 1-1443-B25), with the national funders ANR (French National Research Agency: MC, MVT, TM, WT), FWF (Austrian Science Fund: SD, GK, ID, FE, DM) and DFG (German Research Foundation: MvK., OB, EH, SB), part of the 20122013 BiodivERsA call for research proposals. MC acknowledges support by a Marie
Curie Intra European Fellowship within the European Commission's Seventh Framework Program (FP7-PEOPLE-2012-IEF; IASIMOV 327616). RD and the SAJF acknowledge support from the ANR (grant ANR-11-INBS-0001AnaEE-Services). This study used plant trait values from the TRY initiative and database (http://www.try-db. org). The TRY initiative and database is hosted, developed and maintained by J. Kattge and G. Bonisch (Max Planck Institute for Biogeochemistry, Jena, Germany). TRY is currently supported by DIVERSITAS/Future Earth and the German Centre for Integrative Biodiversity Research (iDiv) Halle-Jena-Leipzig.

\section{ORCID}

Marta Carboni (1D http://orcid.org/0000-0002-9348-4758

Ceres Barros (1) http://orcid.org/0000-0003-4036-977X

\section{REFERENCES}

Alexander, J. M., Kueffer, C., Daehler, C. C., Edwards, P. J., Pauchard, A., Seipel, T., ... Jakobs, G. (2011). Assembly of nonnative floras along elevational gradients explained by directional ecological filtering. Proceedings of the National Academy of Sciences, 108, 656661.

Alexander, J. M., Lembrechts, J. J., Cavieres, L A., Daehler, C., Haider, S., Kueffer, C., ... Pauchard, A. (2016). Plant invasions into mountains and alpine ecosystems: Current status and future challenges. Alpine Botany, 126, 89103.

Becker, T., Dietz, H., Billeter, R., Buschmann, H., \& Edwards, P. J. (2005). Altitudinal distribution of alien plant species in the Swiss Alps. Perspectives in Plant Ecology, Evolution and Systematics, 7, 173183.

Boulangeat, I., Georges, D., Dentant, C., Bonet, R., Van Es, J., Abdulhak, S., ... Thuiller, W. (2014). Anticipating the spatio-temporal response of plant diversity and vegetation structure to climate and land use change in a protected area. Ecography, 37, 12301239.

Boulangeat, I., Georges, D., \& Thuiller, W. (2014). FATE-HD: A spatially and temporally explicit integrated model for predicting vegetation structure and diversity at regional scale. Global Change Biology, 20, 23682378.

Boulangeat, I., Philippe, P., Abdulhak, S., Douzet, R., Garraud, L., Lavergne, S., ... Thuiller, W. (2012). Improving plant functional groups for dynamic models of biodiversity: At the crossroads between functional and community ecology. Global Change Biology, 18,34643475 .

Bradley, B. A., Blumenthal, D. M., Wilcove, D. S., \& Ziska, L. H. (2010). Predicting plant invasions in an era of global change. Trends in Ecology \& Evolution, 25, 310318.

Chytrý, M., Maskell, L. C., Pino, J., Pyšek, P., Vilà, M., Font, X., \& Smart, S. M. (2008). Habitat invasions by alien plants: A quantitative comparison among Mediterranean, subcontinental and oceanic regions of Europe. Joumal of Applied Ecology, 45, 448458.

Colautti, R. I., Grigorovich, I. A., \& Maclsaac, H. J. (2007). Propagule pressure: A null model for biological invasions. Biological Invasions, 9, 885.

Dormann, C. F., Schymanski, S. J., Cabral, J., Chuine, I., Graham, C, Hartig, F., ... Schröder, B. (2012). Correlation and process in species distribution models: Bridging a dichotomy. Journal of Biogeography, 39, 21192131.

Dullinger, S., Dirnböck, T., \& Grabherr, G. (2004). Modelling climate change-driven treeline shifts: Relative effects of temperature increase, dispersal and invasibility. Journal of Ecology, 92, 241252.

Dullinger, I., Wessely, J., Bossdorf, O., Dawson, W., Essl, F., Gattringer, A., ... Dullinger, S. (2016). Climate change will increase the 
naturalization risk from garden plants in Europe. Global Ecology and Biogeography, 26, 4353.

Engler, R., Randin, C. F., Thuiller, W., Dullinger, S., Zimmermann, N. E., Araujo, M. B., ... Guisan, A. (2011). 21st century climate change threatens mountain flora unequally across Europe. Global Change Biology, 17, 23302341.

Eskelinen, A., Kaarlejärvi, E., \& Olofsson, J. (2017). Herbivory and nutrient limitation protect warming tundra from lowland species' invasion and diversity loss. Global Change Biology, 23, 245255.

Esterni, M., Rovera, G., Bonet, R., Salomez, P., Cortot, H., \& Guilloux, J. (2006). DELPHINE - Découpage de l'Espace en Liaison avec les Potentialités Humaines et en Interrelation avec la Nature. Parc National des Ecrins.

Gallien, L., Douzet, R., Pratte, S., Zimmermann, N. E., \& Thuiller, W. (2012). Invasive species distribution models How violating the equilibrium assumption can create new insights. Global Ecology and Biogeography, 21, 11261136.

Gallien, L., Münkemüller, T., Albert, C. H., Boulangeat, I., \& Thuiller, W. (2010). Predicting potential distributions of invasive species: Where to go from here? Diversity and Distributions, 16, 331342.

Gehrig-Fasel, J., Guisan, A., \& Zimmermann, N. E. (2007). Tree line shifts in the Swiss Alps: Climate change or land abandonment? Journal of Vegetation Science, 18, 571582.

Godde, P., Price, M. F., \& Zimmerman, F. M. (2000). Tourism and development in mountain regions. New York, NY: CABI.

Hastings, A., Cuddington, K., Davies, K. F., Dugaw, C. J., Elmendorf, S., Freestone, A., ... Thomson, D. (2005). The spatial spread of invasions: New developments in theory and evidence. Ecology Letters, 8, 91101.

Hijmans, R. J., Cameron, S. E., Parra, J. L., Jones, P. G., \& Jarvis, A. (2005). Very high resolution interpolated climate surfaces for global land areas. International Journal of Climatology, 25, 19651978.

Hulme, P. E., Brundu, G., Carboni, M., Dehnen-Schmutz, K., Dullinger, S., Early, R., ... Verbrugge, L. N. H. (2017). Integrating invasive species policies across ornamental horticulture supply chains to prevent plant invasions. Journal of Applied Ecology. https://doi.org/10.1111/13652664.12953

Insee (2014). Hautes-Alpes: Des arrivées toujours plus nombreuses. Insee Analyses Provence-Alpes-Cote d'Azur, 3, 14.

Johnston, F. M., \& Pickering, C. M. (2001). Alien plants in the Australian Alps. Mountain Research and Development, 21, 284291.

Kalwij, J. M., Robertson, M. P., \& van Rensburg, B. J. (2008). Human activity facilitates altitudinal expansion of exotic plants along a road in montane grassland, South Africa. Applied Vegetation Science, 11, 491498.

Kattge, J., Diaz, S., Lavorel, S., Prentice, C., Leadley, P., Bonisch, G., ... Wirth, C. (2011). TRY A global database of plant traits. Global Change Biology, 17, 29052935.

Kowarik, I. (1995). Time lags in biological invasions with regard to the success and failure of alien species. In P. Pyšek, K. Prach, M. Rejmánek, \& M. Wade (Eds.), Plant invasions: General aspects and special problems (pp. 15 38). Amsterdam, The Netherlands: SPB Academic Publishing.

Kueffer, C., McDougall, K., Alexander, J., Daehler, C., Edwards, P., Haider, S., .. Reshi, Z. A. (2013). Plant invasions into mountain protected areas: Assessment, prevention and control at multiple spatial scales. In L. C. Foxcroft et al. (Ed.), Plant invasions in protected areas (pp. 89 113). Dordrecht, The Netherlands: Springer.

Landolt, E., Bäumler, B., Erhardt, A., Hegg, O., Klötzli, F., Lämmler, W., ... Wohlgemuth, T. (2010). Flora indicativa. Bern - Stuggart - Wien: Haupt Verlag.

Lembrechts, J. J., Alexander, J. M., Cavieres, L. A., Haider, S., Lenoir, J., Kueffer, C., ... Pauchard, A. (2017). Mountain roads shift native and non native plant species' ranges. Ecography, 40, 353364.

Lenda, M., Skórka, P., Knops, J. M. H., Moroń, D., Tworek, S., \& Woyciechowski, M. (2012). Plant establishment and invasions: An increase in a seed disperser combined with land abandonment causes an invasion of the non-native walnut in Europe. Proceedings of the Royal Society B: Biological Sciences, 279, 1491.

Leung B., Lodge, D. M., Finnoff, D., Shogren, J. F., Lewis, M. A., \& Lamberti, G. (2002). An ounce of prevention or a pound of cure: bioeconomic risk analysis of invasive species. Proceedings of the Royal Society of London B: Biological Sciences, 269, 24072413.

Lockwood, J. L., Cassey, P., \& Blackburn, T. (2005). The role of propagule pressure in explaining species invasions. Trends in Ecology \& Evolution, 20, 223228.

Lockwood, J. L., Cassey, P., \& Blackburn, T. M. (2009). The more you introduce the more you get: The role of colonization pressure and propagule pressure in invasion ecology. Diversity and Distributions, 15, 904910.

Mack, R. N., Simberloff, D., Lonsdale, W. M., Evans, H., Clout, M., \& Bazzaz, F. A. (2000). Biotic invasions: Causes, epidemiology, global consequences, and control. Ecological Applications, 10, 689710.

Marco, A., Lavergne, S., Dutoit, T., \& Bertaudiere-Montes, V. (2010). From the backyard to the backcountry: How ecological and biological traits explain the escape of garden plants into Mediterranean old fields. Biological Invasions, 12, 761779.

Marini, L., Bertolli, A., Bona, E., Federici, G., Martini, F., Prosser, F., \& Bommarco, R. (2013). Beta-diversity patterns elucidate mechanisms of alien plant invasion in mountains. Global Ecology and Biogeography, 22, 450460 .

Maurel, N., Hanspach, J., Kühn, I., Pyšek, P., \& van Kleunen, M. (2016). Introduction bias affects relationships between the characteristics of ornamental alien plants and their naturalization success. Global Ecology and Biogeography, 25, 15001509.

McDougall, K. L., Morgan, J. W., Walsh, N. G., \& Williams, R. J. (2005). Plant invasions in treeless vegetation of the Australian Alps. Perspectives in Plant Ecology, Evolution and Systematics, 7, 159171.

Nobis, M. P., Jaeger, J. A. G., \& Zimmermann, N. E. (2009). Neophyte species richness at the landscape scale under urban sprawl and climate warming. Diversity and Distributions, 15, 928939.

Pauchard, A., Kueffer, C., Dietz, H., Daehler, C. C., Alexander, J., Edwards, P. J., ... Seipel, T. (2009). Ain't no mountain high enough: Plant invasions reaching new elevations. Frontiers in Ecology and the Environment, 7, 479486.

Pauchard, A., Milbau, A., Albihn, A., Alexander, J., Burgess, T., Daehler, C., ... Greenwood, G. B. (2016). Non-native and native organisms moving into high elevation and high latitude ecosystems in an era of climate change: New challenges for ecology and conservation. Biological Invasions, 18, 345353.

Petitpierre, B., McDougall, K., Seipel, T., Broennimann, O., Guisan, A., \& Kueffer, C. (2016). Will climate change increase the risk of plant invasions into mountains? Ecological Applications, 26, 530544.

Phillips, S. J., Dudík, M., Elith, J., Graham, C. H., Lehmann, A., Leathwick, J., \& Ferrier, S. (2009). Sample selection bias and presence-only distribution models: Implications for background and pseudo-absence data. Ecological Applications, 19, 181197.

Pickering, C., Hill, W., \& Green, K. (2008). Vascular plant diversity and climate change in the alpine zone of the Snowy Mountains, Australia. Biodiversity and Conservation, 17, 16271644.

Pinheiro, J., Bates, D., DebRoy, S., \& Sarkar, D. (2007). nlme: Linear and nonlinear mixed effects models. R package version 3.1-131. Retrieved from https://CRAN.R-project.org/package nlme

Pruchniewicz, D. (2017). Abandonment of traditionally managed mesic mountain meadows affects plant species composition and diversity. Basic and Applied Ecology, 20, 1018.

Sala, O. E., Chapin, F. S., Armesto, J. J., Berlow, E., Bloomfield, J., Dirzo, R., ... Wall, D. H. (2000). Biodiversity Global biodiversity scenarios for the year 2100. Science, 287, 17701774.

Sanderson, E. W., Jaiteh, M., Levy, M. A., Redford, K. H., Wannebo, A. V., \& Woolmer, G. (2002). The Human Footprint and the Last of the 
Wild: The human footprint is a global map of human influence on the land surface, which suggests that human beings are stewards of nature, whether we like it or not. BioScience, 52, 891904.

Sax, D. F., \& Gaines, S. D. (2008). Species invasions and extinction: The future of native biodiversity on islands. Proceedings of the National Academy of Sciences of the United States of America, 105, 11490 11497.

Seipel, T., Kueffer, C., Rew, L. J., Daehler, C. C., Pauchard, A., Naylor, B. J., ... Arevalo, J. R. (2012). Processes at multiple scales affect richness and similarity of non-native plant species in mountains around the world. Global Ecology and Biogeography, 21, 236246.

Theoharides, K. A., \& Dukes, J. S. (2007). Plant invasion across space and time: Factors affecting nonindigenous species success during four stages of invasion. New Phytologist, 176, 256273.

Thuiller, W., Guéguen, M., Georges, D., Bonet, R., Chalmandrier, L., Garraud, L., .. Zimmermann, N. E. (2014). Are different facets of plant diversity well protected against climate and land cover changes? A test study in the French Alps. Ecography, 37, 12541266.

Thuiller, W., Lafourcade, B., Engler, R., \& Araujo, M. B. (2009). BIOMOD A platform for ensemble forecasting of species distributions. Ecography, 32, 369373.

Traveset, A., \& Richardson, D. M. (2014). Mutualistic interactions and biological invasions. Annual Review of Ecology, Evolution, and Systematics, 45, 89113.

Van Kleunen, M., \& Johnson, S. D. (2007). South African Iridaceae with rapid and profuse seedling emergence are more likely to become naturalized in other regions. Journal of Ecology, 95, 674681.
Vavra, M., Parks, C. G., \& Wisdom, M. J. (2007). Biodiversity, exotic plant species, and herbivory: The good, the bad, and the ungulate. Forest Ecology and Management, 246, 6672.

Weber, E. (2005). Invasive plant species of the world. Wallingford, UK: CABI Publishing.

Williamson, M., \& Fitter, A. (1996). The varying success of invaders. Ecology, 77, 16611666.

Wilson, J. R. U., Dormontt, E. E., Prentis, P. J., Lowe, A. J., \& Richardson, D. M. (2009). Something in the way you move: Dispersal pathways affect invasion success. Trends in Ecology \& Evolution, 24, 136144. 